\title{
LA PLURINACIONALIDAD DEL ESTADO Y LAS APORÍAS DEL LIBERALISMO
}

\author{
PABLO DÁVALOS* \\ Pontificia Universidad Católica del Equador
}

La revista ecuatoriana Opción Socialista, en su edición de los meses de mayo, junio y julio de 2013, ha publicado un Dossier sobre la plurinacionalidad del Estado en el Ecuador ${ }^{1}$. En este dossier constan, entre otros, dos textos que, por la importancia y las consecuencias que tienen quizá sea conveniente analizarlos y referirlos a un debate más amplio: "Plurinacionalidad vs Interculturalidad" de Enrique Ayala Mora, y "Un Estado Plurinacional sin proyecto pero con opciones" de Jorge León Trujillo.

Ahora bien, la primera sensación con respecto a estos textos es una especie de déjà $v u$. En efecto, este debate, al menos en los términos que han sido planteados por los autores citados, recorrió toda la década de los años noventa y tuvo su epítome en los años 2007 y 2008 cuando se estaba discutiendo en Ecuador sobre el carácter del Estado en la Asamblea Constituyente de Montecristi.

En esa oportunidad, el movimiento indígena ecuatoriano y algunos teóricos, entre ellos Boaventura de Souza Santos ${ }^{2}$ y Catherine Walsh', aclararon lo que significaba la plurinacionalidad y la interculturalidad. Demostraron que esos conceptos nunca eran opuestos sino

\footnotetext{
* Economista ecuatoriano. Profesor universitario. Coordinador del Grupo de Trabajo de CLACSO: Movimientos Indígenas en América Latina.

1 Hay una versión electrónica en el siguiente link: http://es.scribd.com/doc/151543172/Revista-opcion-socialista-edicion-especial (visita de septiembre de 2013)

${ }^{2}$ Souza Santos de, Boaventura 2010: Descolonizar el saber, reinventar el poder, Ed. Trilce, Uruguay.

${ }^{3}$ Walsh, Catherine 2012: Interculturalidad crítica y (de) colonialidad. Ensayos desde Abya Yala. Serie Pensamiento Decolonial. Ed. Abya-Yala, Quito-Ecuador.
} 
complementarios y que, de alguna manera, formaban parte de la propuesta teórica y política de las teorías de la decolonialidad y de la filosofía de la liberación en Abya Yala (América Latina).

El entonces relator de Naciones Unidas para los pueblos indígenas, James Anaya, explicó a la Asamblea Constituyente ecuatoriana sobre los derechos de los pueblos indígenas y el Estado Plurinacional indicando que en el año 2007 la Asamblea General de Naciones Unidas, con el voto favorable de Ecuador, había reconocido y aprobado derechos para los pueblos indígenas que estaban en la línea de la plurinacionalidad del Estado ${ }^{4}$.

En esa coyuntura, el debate fue intenso y, en ocasiones, acre y a punto de la ruptura sobre todo con las corrientes liberales que veían en la plurinacionalidad un peligro de fraccionamiento del Estado-nación. Finalmente, el movimiento indígena pudo posicionar sus tesis y la Asamblea Constituyente declaró al Ecuador como Estado Plurinacional e Intercultural.

Por ello, llama la atención que en el año 2013, cuando la coyuntura política ecuatoriana se tensa y se comprueba que el gobierno de Alianza País ha creado un sistema político que le permite consolidar, por vez primera al menos desde el retorno a la democracia en 1979, una hegemonía absoluta con una deriva autoritaria y protofascista, nuevamente surja este debate y desde las filas de una revista que tiene la pretensión de inscribirse al interior del pensamiento de la izquierda y del socialismo. La cuestión que inmediatamente se suscita es ¿cuál es la pretensión política al confrontar la plurinacionalidad con la interculturalidad en un contexto político tan conflictivo y en plena intensificación de las dinámicas extractivas?

La segunda sensación que deja la lectura de estos textos es la insuficiencia teórica y reflexiva, en ambos autores, de remitir el debate de la plurinacionalidad a su territorio epistemológico natural, aquel de la teoría decolonial, la filosofía de la liberación y las ontologías políticas de la diferencia radical y que están relacionadas con el pensamiento propio indígena y su proyecto político.

El concepto de la plurinacionalidad del Estado es demasiado complejo como para ser parte de un tratamiento tan superficial y

4 IWGIA 2010: Ecuador: Derechos colectivos de los pueblos y Nacionalidades. Evaluación de una década 1998-2008. Ed. IWGIA-Tukuishimi. Quito-Ecuador. 
pragmático, un tratamiento que, además, corre el riesgo de banalizarlo. El problema real de la plurinacionalidad del Estado no está en las formas institucionales que puede adquirir la plurinacionalidad en el caso del Ecuador y de Bolivia y sus posibles arreglos y acuerdos jurídicos y procedimentales con toda la importancia que pudieran tener.

Cuando se menciona y se debate la plurinacionalidad del Estado aquello que está en juego es la pertinencia y régimen de verdad que sustenta una de las categorías centrales del liberalismo: el Estado-Nación, y esta categoría remite a la narración más fuerte que la burguesía ha creado para legitimarse históricamente, aquella de la modernidad. El debate sobre el Estado Plurinacional es, por definición, un debate sobre los límites y alcances de la modernidad y sus posibilidades de regulación y emancipación.

Por ello, llama la atención el hecho que ambos autores omitan este debate, lo pasen por alto y no le otorguen ninguna importancia para su argumentación. Si soslayan el debate sobre la modernidad, entonces ¿cómo comprender el núcleo duro que sustenta las propuestas del Estado Plurinacional? ¿Cómo comprender el alcance de la interculturalidad y su relación con la Plurinacionalidad? ¿sobre qué piso teórico se pueden confrontarlas o armonizarlas?

En el caso de Enrique Ayala Mora, rector, además, de la sede ecuatoriana de la Universidad Andina Simón Bolívar, y miembro importante del Partido Socialista Ecuatoriano, contrapone en su artículo las contradicciones de clase a la identidad étnica pensando que el Estado Plurinacional es una reivindicación etnicista que poco o nada tiene que ver con las contradicciones de clase $\mathrm{y}$, de esta forma, clausura una rica herencia de la izquierda ecuatoriana y latinoamericana de trabajo comunitario e indígena tanto teórico como político, que en el caso ecuatoriano tiene en Ricardo Paredes y en Agustín Cueva sus puntos importantes, y en el caso latinoamericano están, por supuesto, José Carlos Mariátegui y Aníbal Quijano. De hecho, el movimiento indígena ecuatoriano y latinoamericano, nunca ha soslayado las contradicciones de clase en su lucha por las reivindicaciones identitarias.

Desde una pretendida posición de un socialismo más bien decimonónico, Ayala Mora, plantea una discusión con el estatuto de plurinacionalidad del Estado desde una visión, paradójicamente para él, no socialista, sino liberal. En efecto, es el liberalismo el que niega las condiciones de posibilidad a toda diversidad humana para constituirse 
como "nacionalidad" porque este estatuto altera una de las figuras más caras del liberalismo, aquella del Estado-nación. Es desde el liberalismo que los indígenas han sido acusados de "etno-centristas". Es también una visión liberal la que acusa de corporativismo al movimiento indígena porque plantea que los indígenas apelan a un estatuto de diferencias desde una reivindicación histórica y ancestral que intenta fracturar radicalmente la unidad jurídica de la ciudadanía y del contrato social. Asimismo, Ayala Mora sitúa su crítica a la plurinacionalidad del Estado desde la trama epistemológica del multiculturalismo; sin embargo, el multiculturalismo siempre fue denunciado por ser parte de una estrategia neoliberal de incluir las diferencias al interior de la globalización y el mercado 5 .

No solo eso, sino que en el texto de Ayala Mora, hay frases muy reveladoras de su ideología, como ésta: "Pero, justo es reconocerlo, el etnocentrismo no es mayoritario. Los indígenas ecuatorianos aman al país; se sienten parte de él." (loc. cit. pp. 28). La visión liberal de Ayala Mora llega, además, a contraponer la interculturalidad a la plurinacionalidad, pero la interculturalidad a la que hace referencia no es el discurso fuerte que contrapone a la formación discursiva del poder un saber contrahegemónico obligándolo a lo que Boaventura de Souza Santos llama un "diálogo de saberes" o fracturando aquello que Mignolo denomina la "geopolítica del conocimiento", sino una especie de visión liberal de la interculturalidad en su versión multicultural que, en realidad, encubre una maniobra política, aquella de poner al movimiento indígena en contra de sí mismo.

El caso de Jorge León Trujillo también es sintomático en ese sentido porque confunde los derechos colectivos con el Estado Plurinacional y, lo que es más grave, no se da cuenta que con la declaración de Estado de derechos y justicia para el Estado ecuatoriano, conforme al Art. 1 de la Constitución Política de 2008, los derechos colectivos no existen como derechos diferenciados. La visión de Jorge León Trujillo recuerda mucho aquella propuesta de la plurinacionalidad que tenía el Banco Mundial y la cooperación internacional al desarrollo, es decir, una visión instrumentalista, pragmática y estratégica, que veía en la plurinacionalidad solamente una dimensión acotada de autonomía de los gobiernos locales en el manejo territorial al interior de la división política del Estado, sin cambiar para nada las relaciones de poder que definen y estructuran al

5 Cfr. Zizek, Slavoj 1997: Multuculturalism, or the Cultural Logic of Multinational Capitalism. En: New Left Review, 225, 28-51. 
Estado y sus discursos. La apelación a las circunscripciones territoriales, a las que hace referencia León Trujillo, no topan el núcleo central y es aquel de la soberanía sobre los territorios y sus recursos que reclaman los pueblos indígenas no para explotarlos sino para integrarlos en su cosmovisión a la que han dado el nombre de Sumak kawsay para el caso ecuatoriano, y Suma Qamaña para el caso boliviano.

Ahora bien, más allá de señalar los límites teóricos de estos textos y su probable conversión en posteriores dispositivos políticos que servirán como argumentos para desarmar la capacidad política de movilización del movimiento indígena, sobre todo en su defensa de los territorios en contra de la violencia extractiva, quizá sea conveniente retomar el debate sobre lo que significa la plurinacionalidad del Estado, al momento una de las categorías políticas más complejas creada desde la praxis política del movimiento indígena ecuatoriano y también boliviano y que ahora ha sido recogida por la mayor parte de movimientos indígenas del Abya Yala (América Latina). Por ello, y aprovechando la oportunidad que brindan los dos textos antes señalados, quizá sea conveniente devolver nuevamente el debate de la plurinacionalidad del Estado y la interculturalidad a su topos natural, aquel de las teorías de la decolonialidad, la filosofía de la liberación así como las ontologías políticas de las diferencias radicales para, desde ahí, evaluar el recorrido de la plurinacionalidad y la interculturalidad en los casos de Ecuador y Bolivia.

La primera reflexión en ese sentido es que la categoría de Plurinacionalidad del Estado forma parte de la ontología política del movimiento indígena. En efecto, de la misma manera que la burguesía se constituyó ontológicamente recuperando la noción de "Hombre" desde el renacimiento europeo y ontologizó esa noción para situarla como condición de posibilidad para el contrato social como fundamento moderno del poder, el movimiento indígena acude a la noción de Estado Plurinacional para lograr visibilidad ontológica como diferencia radical y, al mismo tiempo, denunciar el estatuto violento del Estado-nación moderno y burgués.

El Estado Plurinacional es la imputación a la figura del EstadoNación y sus nociones de contractualidad y libertad individual, como dinámicas de violencia, dominación y colonialidad. Esa colonialidad se expresa en el caso de los pueblos y naciones indígenas en su virtual invisibilización y desaparición ontológica. Es tan evidente esa invisibilización ontológica que los indígenas ecuatorianos accedieron al estatuto de ciudadanía política recién en el año 1998. 
La invisibilización ontológica a los pueblos y naciones indígenas, forma parte de aquello que Aníbal Quijano denomina la colonialidad del poder $^{6}$, así como de su naturalización en aquello que Walter Mignolo denomina la diferencia colonial. Uno de los mecanismos de la colonialidad del poder y de la diferencia colonial fue el racismo y la generación de discursos, dispositivos e instituciones que mantenían y profundizaban la dominación política desde la idea de "raza". La ideología del racismo siempre sustentó el régimen de dominación política en Abya Yala (América Latina) desde la conquista europea hasta la actualidad.

Esa idea de "raza" articulaba de forma coherente y estratégica la dominación política a los indígenas y los separaba radicalmente de cualquier posibilidad de crítica y emancipación desde su propia ontología política. Para criticar al racismo de la colonialidad del poder, los indígenas tenían que utilizar la misma ideología que los invisibilizaba ontológicamente.

La idea de raza como dispositivo del poder colonial también colonizó la forma de comprender al mundo y la forma de ser-en-el-mundo, así como la capacidad de interpretarlo y transformarlo. La idea de "raza" es el envés de la ontología política de la burguesía: para afirmar su ser-en-elmundo, ésta tiene que negar radicalmente aquello que no consta dentro de sus marcos ontológicos de existencia. Esa negación ontológica que es el correlato teórico y filosófico de la colonialidad del poder y de la diferencia colonial tiene también un correlato político, ideológico, cultural, jurídico y epistemológico. La ontología política de la burguesía, en consecuencia, siempre es violenta, discriminadora, excluyente.

La colonialidad del poder hizo de los indígenas del Abya Yala (América Latina) el Otro radical a la modernidad. Los excluyó de toda forma de racionalidad humana entendida ésta en los términos modernos. Los alejó de forma definitiva de todo horizonte de lo humano en cuanto humano. Los deshumanizó de forma radical y absoluta. Solo desde esa deshumanización era posible colonizarlos, someterlos, dominarlos. Esa

${ }^{6}$ Quijano, Aníbal 1999. La colonialidad del poder. Cultura y conocimiento en América Latina. En: Castro-Gómez, Santiago et alt Eds. Pensar (en) los intersticios. Teoría y práctica de la crítica poscolonial. Perspectivas latinoamericanas. CLACSO, Buenos Aires.

7 Mignolo, Walter 2000. Diferencia colonial y razón post occidental. En: CastroGómez, Santiago, Ed. La reestructuración de las ciencias sociales en América Latina. Bogotá, Centro Editorial Javeriano, 3-28. 
deshumanización implicaba que los indígenas en cuanto indígenas habían sido desalojados y despojados de toda consideración ontológica. Para existir tenían que situarse dentro del horizonte de visibilidad de la modernidad, fuera de ese horizonte, no existían.

Enrique Dussel, afirma que la modernidad no nace con el cogito cartesiano sino con el ego conquiro europeo. En 1492 se produjo, en realidad, el en-cubrimiento del Otro ${ }^{8}$. A partir de ese entonces, el Otro dejó de existir como Alteridad. Para existir, el Otro tenía que perder su estatuto de diferencia radical y permitir ser incorporado a los sistemas y mecanismos de dominación. Tenía que ser incluido a la modernidad y al capitalismo por la vía de la modernización, la civilización, la educación, la economía-mundo, etc., es decir, situarse en ese horizonte ontológico de visualización de la modernidad o, caso contrario, desaparecer.

Sin embargo, la modernidad es autorreferencial y autopoiética. Agota en sí misma incluso su propia crítica. La modernidad no acepta a Otro radical porque ello implicaría relativizar sus propios contenidos universalistas. Significaría reconocer los límites de su propio horizonte de visibilidad; empero, la modernidad asume esos límites como inexistentes porque comprende y pronuncia al mundo desde la universalidad. Esa condición de universalidad es clave para su pretensión civilizatoria. La universalidad de la razón moderna es totalizante y totalitaria. La modernidad está enferma de totalidad. Fuera de esa frontera de la totalidad nada ni nadie puede ni debe existir (Lo racional es real escribía Hegel ${ }^{9}$ ). La totalidad establece una frontera para Lo Real en cuanto Real desde las propias prescripciones modernas. Nada puede existir fuera de esa frontera de Lo Real.

No obstante, el Otro en cuanto Otro es la evidencia de que hay algo fuera de esa frontera de racionalidad y realidad impuesta desde la modernidad. Es una exterioridad radical que amenaza a la modernidad en sí misma. Fue el pensador francés Emmanuel Levinas quien, entre otros, teorizó sobre el estatuto de la exterioridad y la alteridad radical. El Otro es Alteridad radical porque se sitúa al exterior de aquello que Levinas denomina Lo Mismo. El Otro como Alteridad radical no puede ser parte de Lo Mismo. Es una exterioridad irreductible a Lo Mismo. Entre la Alteridad

${ }^{8}$ Cfr. Dussel, Enrique 1994. $1492 \mathrm{El}$ encubrimiento del Otro. Hacia el origen del "mito de la Modernidad". Plural Editores-Universidad Mayor de San Andrés, La Paz-Bolivia. ${ }^{9}$ Cfr. Hegel, G. W. 1998. Fenomenología del Espíritu. FCE. México. 
radical y Lo Mismo no puede mediar una dialéctica que integre al Otro dentro del canon de Lo Mismo.

Ahora bien, en la idea de raza de la colonialidad del poder y de la diferencia colonial, el Otro en cuanto Otro es despojado de toda consistencia ontológica. Esa Alteridad radical, para la modernidad, debe desaparecer en tanto que tal. La modernidad subsiste y persiste a condición de suprimir cualquier exterioridad a ella, vale decir, a la Alteridad radical. Fue Franz Fanon quien denunció esa "desaparición ontológica" del Otro en el colonialismo. Fanon también denunciaba la estrategia colonial de convertir al Otro en un permanente menor de edad que debe ser protegido de sí mismo. Esa conversión en menor de edad justificaba la intervención colonial y su violencia. Ahí radica, decía Fanon la desgracia ontológica del Otro, es decir, su conversión, desde la mirada colonial, como un ser fundamentalmente perverso, malo, destinado a destruirse a sí mismo ${ }^{10}$.

Para esta visión colonial, el Otro es un ser en permanente devenir hacia el Ser-que-es-Real, es decir, el Ser moderno. Pero en ese devenir, el Otro no se encuentra a sí mismo, se pierde en los laberintos de su propia ontología y es necesario ayudarlo a salir porque, caso contrario, esa pérdida le puede conducir a la noche-del-mundo. En esa noche-del-mundo en la que vive el Otro, éste no tiene opciones. Y no las tiene porque su pasado es, precisamente, esa noche-del-mundo, esa oscuridad de la razón. El Otro, dice el colonialista, ha vivido siempre en las tinieblas. Sus referentes, su memoria histórica, son la constatación de esa noche-del-mundo. El espíritu moderno viene a "iluminarlo", a sacarlo de la noche-del-mundo; viene a hacerle comprender que vive en la noche-del-mundo y que incluso la violencia de la civilización es, en el fondo, una violencia benéfica porque toda luz lastima a quien ha vivido mucho tiempo en la oscuridad. Es necesario alfabetizarlo en los códigos que le permitan comprender que su Ser está perdido irremisiblemente en esa noche-del-mundo y que, para salir de esa noche-del-mundo, tiene que abandonar su Ser en cuanto Ser, tiene que dejar de ser Otro y convertirse en Lo Mismo. Ese tránsito es presentado desde la visión del colonialista como una salvación, como una oportunidad.

Este proceso de supuesta violencia benéfica de la modernidad y la civilización con respecto al Otro está presente en la forma que se conforma el Estado-Nación en toda Abya Yala (América Latina) y también, por

${ }^{10}$ Fanon, Franz 2007. Los Condenados de la Tierra. Ed. Colectivo Editorial Último Recurso. Argentina 
supuesto, en Ecuador. Efectivamente, luego de los procesos de independencia de la metrópoli española en Abya Yala nace una aberración jurídica y un imposible político: un Estado de forma moderna y liberal, en sociedades en las que no existen ciudadanos, burguesía, ni ninguna institución moderna. Constituir Estados-nación en un contexto de sociedades coloniales y colonizadas, en donde la inmensa mayoría de la población nada tiene que ver con la modernidad, ni con el naciente capitalismo, es un desafío al principio de realidad. Solo desde el ethos barroco del Abya Yala pudo procesarse esta aberración jurídico-política y otorgarle condiciones de posibilidad.

Mas, ese Estado-Nación desde sus orígenes procesó la colonialidad del poder, la desaparición ontológica del Otro y la diferencia colonial del racismo. En la primera Constitución del Ecuador, aquella de 1830, se decía con respecto a los indígenas:

“Artículo 68.- Este Congreso constituyente nombra a los venerables curas párrocos por tutores y padres naturales de los indígenas, excitando su ministerio de caridad en favor de esta clase inocente, abyecta y miserable."

Los indígenas del Abya Yala, son la clase inocente, abyecta y miserable que, dos siglos después, y por las paradojas del liberalismo: "aman al país; se sienten parte de él".

Esta estrategia de colonizar el Ser en cuanto Ser de las Alteridades Radicales y desaparecerlos de todo horizonte ontológico, puede ser denominada como invisibilización ontológica. En la matriz epistemológica e incluso axiológica de la modernidad subyacen todas las condiciones de posibilidad que definen y procesan esa invisibilización ontológica del Otro. Esas condiciones de posibilidad asumen varias formas, como por ejemplo:

La lógica de la desaparición: El Otro no existe.

La deontología de la violencia radical moderna: El Otro no debe existir

La lógica de la asimilación: El Otro, para Ser, debe ser incluido

La lógica de la indiferenciación: El Yo siempre es un Otro

La lógica del olvido: El Otro aún no es

La lógica de la ausencia: El Otro nunca será

La lógica de la distancia insalvable: El Otro nunca ha sido 

mismo

La lógica de la desgracia ontológica: El Otro debe ser protegido de sí

La invisibilización ontológica es un proceso violento y sin remisión posible. Los pueblos indígenas del Abya Yala, han sufrido y aún sufren en carne propia todas estas dinámicas de la invisibilización ontológica: han sido objeto del exterminio sistemático y el genocidio (no deben existir); han sido parte de una sistemática estrategia de negación y su memoria e historia han sido permanentemente escamoteadas (no existen, nunca han existido); han formado parte de las estrategias de inclusión y sometimiento de las políticas indigenistas de sus Estados o de la cooperación internacional (deben ser incluidos); han sido la materia prima de las políticas de modernización, desarrollo, inclusión, etc. (aún no son pero algún momento llegarán a Ser); han sido considerados como permanentes menores de edad (deben ser protegidos de sí mismos), etc.

Como en el Ministerio de la Verdad de la distopía de Orwell y que se encargaba de reescribir la historia para concordarla con el poder ${ }^{11}$, la memoria histórica de los pueblos del Abya Yala ha sido sistemáticamente saqueada, destruida, olvidada, negada, preterida. En el Ecuador, el gobierno progresista de Alianza País eliminó la educación intercultural bilingüe y emitió un decreto ejecutivo para entregar los territorios amazónicos de los pueblos y naciones indígenas que los habitan a la labor misionera y evangélica de la iglesia católica.

Una de las figuras centrales de esta invisibilización ontológica ha sido aquella del Estado-nación moderno y liberal. Es desde el Estadonación moderno que se procesan esas lógicas de la desaparición e invisibilización ontológica a las diferencias radicales. Al contrario de la teoría liberal que ve en el Estado la racionalidad individual de la contractualidad y el espacio de la libertado individual y la maximización del beneficio personal, la teoría y crítica de la plurinacionalidad del Estado propuesta desde los movimientos indígenas, obliga a visualizarlo como una forma de dominación política que procesa no solo las diferencias de clase, sino que garantiza la colonialidad del poder, la diferencia colonial, las geopolíticas del conocimiento y las lógicas de la invisibilización ontológicas de las diferencias radicales. Son justamente estos procesos los que no son advertidos en los textos de Ayala Mora y León Trujillo.

${ }^{11}$ Cfr. Orwell, George 1980: 1984. Salvat Editores, Barcelona-España. 
La teoría decolonial, la filosofía de la liberación y los propios movimientos indígenas han puesto en relieve los discursos de poder que colonizan al Otro y lo despojan de su ontología. Por ello, una de las primeras formas de resistencia es, como lo diría John Holloway, el grito, porque ese grito representa el "existo", el "soy", el Ser que es negado por la colonialidad del poder y la diferencia colonial, y que reclama, desde el grito, la existencia y el reconocimiento de esa existencia ${ }^{12}$.

Quizá el concepto de Estado-Plurinacional pueda ser asumido como parte de ese grito, de esa disonancia que viene, precisamente, de la nochedel-mundo. De esa noche que es la memoria ancestral que resiste al olvido intencional. El Estado Plurinacional es la grieta en la hegemonía liberal del Estado-nación. Oponer la plurinacionalidad del Estado con la interculturalidad de la sociedad equivale a operar al interior de la lógica colonial y violenta de la matriz moderna, y negar la capacidad del movimiento indígena de crear su propia ontología política. Equivale a clausurar uno de los procesos históricos más ricos, extraordinarios y emancipatorios del continente y también del mundo, porque la interculturalidad es el espacio ontológico desde el cual el Otro puede construirse ontológicamente. Asimismo, inscribir la plurinacionalidad del Estado al interior de la trama liberal de la política y de su visión instrumental y estratégica de los territorios equivale a eliminar todo potencial emancipatorio del movimiento indígena como sujeto histórico y social.

Los problemas que subsisten en Ecuador y Bolivia, los primeros países del mundo en reconocerse como Estados plurinacionales, no dan cuenta de las carencias que tendría la plurinacionalidad como horizonte emancipatorio sino del formato en el que están inscritos: aquel del liberalismo y su propuesta de contractualidad individual y estratégica.

El Estado plurinacional como propuesta del movimiento indígena, no quiere ni nunca ha sido su pretensión, el crear un estatuto de autonomía o libre determinación para los pueblos indígenas en un contexto de colonialidad y violencia social. Mientras exista ese contexto de violencia y que es inherente tanto a la modernidad cuanto al capitalismo, la plurinacionalidad es un horizonte de visibilidad para la emancipación.

\footnotetext{
${ }^{12}$ Holloway, John 2010. Cambiar el mundo sin tomar el poder. Sísifo Ediciones, Bajo Tierra Ediciones. México D.F.
} 
En ese sentido, una evaluación de la plurinacionalidad del Estado, luego de su incorporación a los textos constitucionales de Ecuador y Bolivia no parte desde el lado indígena de la ecuación ni tampoco de su lado liberal, sino de su integralidad y su dialéctica. Tanto en Ecuador como en Bolivia, la declaratoria de plurinacionalidad del Estado no ha frenado las derivas depredadoras de la acumulación del capital y sus dinámicas extractivistas; más bien ha sido utilizado en contra de la capacidad de movilización y resistencia de los pueblos indígenas y de la organizaciones sociales. Parece una paradoja que la declaratoria de plurinacionalidad del Estado permita una mayor criminalización a los pueblos indígenas por defender precisamente aquello que define la plurinacionalidad: los territorios, sus recursos y sus modos de vida. Empero, el problema real no está en la plurinacionalidad sino en el formato que la cobija: el Estado liberal y el sustrato de realidad que lo determina: los procesos de acumulación del capital.

Quizá sea conveniente establecer un paralelismo histórico con la conformación de la burguesía. Cuando la burguesía propuso la ciudadanía política para refundar al Estado monárquico y feudal, se dio cuenta que esa propuesta de libertad individual y de igualdad jurídica era imposible de conjugarse con los Estados monárquicos y autoritarios. El Estado feudal era un límite histórico para el Estado liberal que la burguesía proponía. El concepto de libertad individual chocaba con la estructura feudal del poder. La burguesía necesitaba tanto de una economía política de la mercancía cuanto de una economía política de la libertad individual. Quizá a su pesar, pero la burguesía tuvo que adquirir una contextura revolucionaria para abrir el espacio social a sus propias prerrogativas y reinventarse el mundo. Ahora, en cambio, estamos llegando al límite del Estado liberal. Las categorías de plurinacionalidad del Estado y de interculturalidad evidencia esos límites.

El problema de fondo y aquello que debe ser criticado es, precisamente, el formato liberal del Estado, de la política y de la sociedad en el contexto de una acumulación del capital signada por la preeminencia del capital financiero. Quizá la conclusión más importante que puede realizarse luego de la declaratoria de plurinacionalidad del Estado en Ecuador y en Bolivia es que ese concepto, al parecer, resulta incompatible con el formato liberal de la política y la acumulación capitalista.

Si en algún momento se pensó que los derechos colectivos de alguna manera constituían una garantía y una posibilidad de defensa de los territorios y de la vida de los pueblos y naciones del Abya Yala 
amenazados por el capitalismo y la modernidad, los nuevos procesos políticos de Ecuador y Bolivia no solo dan cuenta de que la acumulación del capital es despiadada con todo aquello que se le opone y hace de la teoría de los derechos un simulacro del poder, sino que esa teoría que fundamenta al poder moderno desde el interés general, los derechos humanos, la libertad individual, forma también parte de ese simulacro. En consecuencia, es necesario pensar en otro formato para la política, para el Estado y, por supuesto, para la economía; un formato que rebase radicalmente al liberalismo.

Los impasses de la plurinacionalidad del Estado radican, en consecuencia, en el formato liberal-capitalista de la historia. Quizá sea momento de empezar a salir de forma radical del esquema liberal de la política y sus conceptos de democracia representativa, de reglas de la mayoría, de ciudadanías, de agentes representativos, etc., por conceptos que enriquezcan a la democracia y a la política desde otras perspectivas. Quizá sea momento de detener la deriva depredadora de la acumulación del capital y los simulacros del liberalismo y hacer una apuesta por la vida, tal como fue, en sus orígenes, la propuesta emancipatoria de la liberación del trabajo y de la explotación.

Walter Benjamin decía que la utopía debe servirnos para iluminar aquello que debemos destruir. La plurinacionalidad del Estado es esa utopía que permite comprender la violencia intrínseca del Estado-Nación, de la acumulación capitalista y de sus discursos legitimantes, en la ocurrencia, el liberalismo político, jurídico y económico.

\section{LA PLURINACIONALIDAD DEL ESTADO Y LAS APORÍAS DEL LIBERALISMO}

Resumen: La plurinacionalidad del Estado forma parte del proyecto político del movimiento indígena ecuatoriano y boliviano es también parte de su ontología política como alteridades radicales a la modernidad. La recuperación de la ontología política del movimiento indígena permite confrontar el estatuto de violencia inherente a la forma Estado-nación, así como a los discursos que lo legitiman, fundamentalmente, el liberalismo. El Estado-nación moderno ha procesado la invisibilización y desaparición ontológica de las alteridades radicales a través de varios procesos políticos, jurídicos e institucionales. Para confrontar esa violencia y ese estatuto de invisibilización y desaparición ontológica, se ha propuesto la plurinacionalidad del Estado desde la praxis política e histórica de los indígenas como sujetos sociales. 
Palabras claves: plurinacionalidad del Estado, ontologías políticas de la diferencia radical, invisibilización y desaparición ontológica, liberalismo.

\section{THE PLURINATIONAL STATE AND THE LIBERALISM APORIA}

Abstract: The plurinational state political project is part of the Ecuadorian and Bolivian indigenous movement, is also part of his political ontology as radical otherness modernity. The recovery of the indigenous movement's political ontology allows status confront violence inherent in the modern nation-state, well as the discourses that legitimize modern State, basically the liberalism. The modern nation-state has processed the disappearance ontological invisibility and radical otherness through various political, legal and institutional mechanisms. To confront such violence and the status of invisibility and ontological disappearance has been proposed state plurinationality from political and historical praxis of indigenous as social subjects.

Keywords: plurinational state, political ontologies of radical difference, invisibility and disappearance ontology, liberalism.

\section{BIBLIOGRAFÍA}

AYALA MORA, Enrique (2013). "Plurinacionalidad vs Interculturalidad" Revista Opción Socialista:http://es.scribd.com/doc/151543172/Revista-opcionsocialista-edicion-especial (visita de septiembre de 2013)

DUSSEL, Enrique (1994. 1492). El encubrimiento del Otro. Hacia el origen del "mito de la Modernidad". Plural Editores-Universidad Mayor de San Andrés, La Paz-Bolivia.

FANON, Franz (2007). Los Condenados de la Tierra. Ed. Colectivo Editorial Último Recurso. Argentina 
HEGEL, G. W. (1998). Fenomenología del Espíritu. FCE. México.

HOLLOWAY, John (2010). Cambiar el mundo sin tomar el poder. Sísifo Ediciones, Bajo Tierra Ediciones. México D.F.

IWGIA (2010). Ecuador: Derechos colectivos de los pueblos y Nacionalidades. Evaluación de una década 1998-2008. Ed. IWGIA-Tukuishimi. Quito-Ecuador. LEÓN TRUJILLO, Jorge (2013). “Un Estado Plurinacional sin proyecto pero con opciones" Revista Opción Socialista: http://es.scribd.com/doc/151543172/Revista-opcion-socialista-edicion-especial, (visita de septiembre de 2013)

MIGNOLO, Walter (2000). Diferencia colonial y razón post occidental. En: Castro-Gómez, Santiago, Ed. La reestructuración de las ciencias sociales en América Latina. Bogotá, Centro Editorial Javeriano, 3-28.

ORWELL, George (1980: 1984). Salvat Editores, Barcelona-España.

QUIJANO, Aníbal (1999). La colonialidad del poder. Cultura y conocimiento en América Latina. En: Castro-Gómez, Santiago et alt Eds. Pensar (en) los intersticios. Teoría y práctica de la crítica poscolonial. Perspectivas latinoamericanas. CLACSO, Buenos Aires.

SOUZA SANTOS de, Boaventura (2010): Descolonizar el saber, reinventar el poder, Ed. Trilce, Uruguay.

WALSH, Catherine (2012). Interculturalidad crítica y (de) colonialidad. Ensayos desde Abya Yala. Serie Pensamiento Decolonial. Ed. Abya-Yala, Quito-Ecuador. ZIZEK, Slavoj (1997). Multuculturalism, or the Cultural Logic of Multinational Capitalism. En: New Left Review, 225, 28-51. 